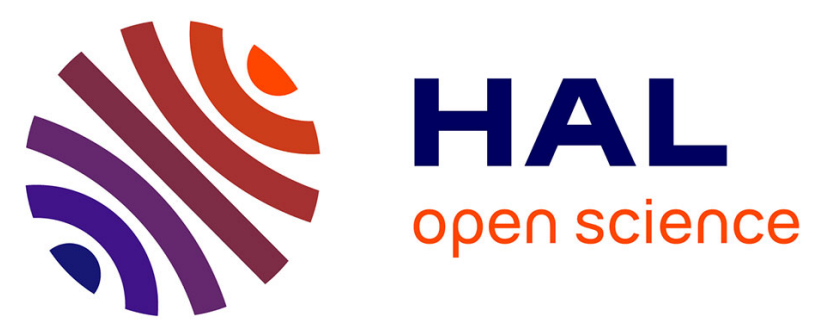

\title{
A 3D lower limb musculoskeletal model for simultaneous estimation of musculo-tendon, joint contact, ligament and bone forces during gait
}

Florent Moissenet, Laurence Cheze, Raphaël Dumas

\section{- To cite this version:}

Florent Moissenet, Laurence Cheze, Raphaël Dumas. A 3D lower limb musculoskeletal model for simultaneous estimation of musculo-tendon, joint contact, ligament and bone forces during gait. Journal of Biomechanics, 2014, 47 (1), pp.50-58. 10.1016/j.jbiomech.2013.10.015 hal-01417416

\author{
HAL Id: hal-01417416 \\ https://hal.science/hal-01417416
}

Submitted on 15 Dec 2016

HAL is a multi-disciplinary open access archive for the deposit and dissemination of scientific research documents, whether they are published or not. The documents may come from teaching and research institutions in France or abroad, or from public or private research centers.
L'archive ouverte pluridisciplinaire HAL, est destinée au dépôt et à la diffusion de documents scientifiques de niveau recherche, publiés ou non, émanant des établissements d'enseignement et de recherche français ou étrangers, des laboratoires publics ou privés. 


\section{Author's Accepted Manuscript}

A 3D lower limb musculoskeletal model for simultaneous estimation of musculo-tendon, joint contact, ligament and bone forces during gait

Florent Moissenet, Laurence Chèze, Raphaël Dumas

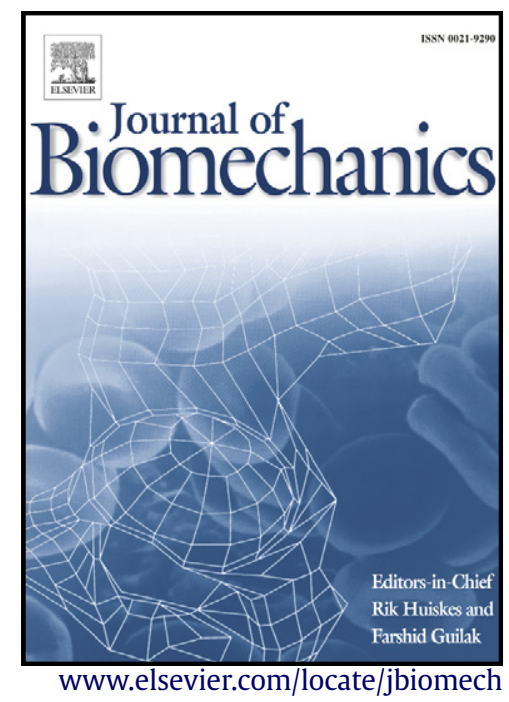

PII: S0021-9290(13)00469-7

DOI: $\quad$ http://dx.doi.org/10.1016/j.jbiomech.2013.10.015

Reference: BM6325

To appear in: Journal of Biomechanics

Received date: 25 March 2013

Revised date: 11 October 2013

Accepted date: 12 October 2013

Cite this article as: Florent Moissenet, Laurence Chèze, Raphaël Dumas, A 3D lower limb musculoskeletal model for simultaneous estimation of musculotendon, joint contact, ligament and bone forces during gait, Journal of Biomechanics, http://dx.doi.org/10.1016/j.jbiomech.2013.10.015

This is a PDF file of an unedited manuscript that has been accepted for publication. As a service to our customers we are providing this early version of the manuscript. The manuscript will undergo copyediting, typesetting, and review of the resulting galley proof before it is published in its final citable form. Please note that during the production process errors may be discovered which could affect the content, and all legal disclaimers that apply to the journal pertain. 
Title: A 3D lower limb musculoskeletal model for simultaneous estimation of musculotendon, joint contact, ligament and bone forces during gait

Article type: Original article

Keywords: Musculoskeletal modeling, musculo-tendon force, joint contact force, ligament force, bone force, musculoskeletal structures interaction, static optimization, model validation

Corresponding author: Florent Moissenet

Corresponding author's intitution: CNRFR - Rehazenter, Laboratoire d'Analyse du Mouvement et de la Posture, 1 rue André Vésale, L-2674 Luxembourg, Luxembourg

First author: Florent Moissenet

Order of authors: Florent Moissenet, Laurence Chèze, Raphaël Dumas

A 3D lower limb musculoskeletal model for simultaneous estimation of musculo-tendon, joint contact, ligament and bone forces during gait

\author{
Florent Moissenet $^{1 \star}$ Laurence Chèze $^{2}$, Raphaël Dumas ${ }^{2}$ \\ ${ }^{1}$ CNRFR - Rehazenter, Laboratoire d'Analyse du Mouvement et de la Posture, \\ 1 rue André Vésale, L-2674 Luxembourg, Luxembourg \\ ${ }^{2}$ Université de Lyon, F-69622, Lyon ; IFSTTAR, LBMC, UMR_T9406 ; \\ Université Lyon 1, France.
}

\title{
* Corresponding author:
}

Florent Moissenet

CNRFR - Rehazenter

Laboratoire d'Analyse du Mouvement et de la Posture

1 rue André Vésale

L-2674 Luxembourg

Luxembourg

florent.moissenet@mailoo.org 
Abstract - Musculo-tendon forces and joint reaction forces are typically estimated using a two-step method, computing first the musculo-tendon forces by a static optimization procedure and then deducing the joint reaction forces from the force equilibrium. However, this method does not allow studying the interactions between musculo-tendon forces and joint reaction forces in establishing this equilibrium and the joint reaction forces are usually overestimated. This study introduces a new 3D lower limb musculoskeletal model based on a one-step static optimization procedure allowing simultaneous musculo-tendon, joint contact, ligament and bone forces estimation during gait. It is postulated that this approach, by giving access to the forces transmitted by these musculoskeletal structures at hip, tibiofemoral, patellofemoral and ankle joints, modeled using anatomically consistent kinematic models, should ease the validation of the model using joint contact forces measured with instrumented prostheses. A blinded validation based on four datasets was made under two different minimization conditions (i.e., C1 - only musculo-tendon forces are minimized, C2 musculo-tendon, joint contact, ligament and bone forces are minimized while focusing more specifically on tibiofemoral joint contacts). The results show that the model is able to estimate in most cases the correct timing of musculo-tendon forces during normal gait (i.e., the mean coefficient of active/inactive state concordance between estimated musculo-tendon force and measured EMG envelopes was C1: 65.87\%, C2: 60.46\%). The results also showed that the model is potentially able to well estimate joint contact, ligament and bone forces and more specifically medial (i.e., the mean RMSE between estimated joint contact force and in vivo measurement was C1: 1.14BW, C2: 0.39BW) and lateral (i.e., C1: 0.65BW, C2: 0.28BW) tibiofemoral contact forces during normal gait. However, the results remain highly influenced by the optimization weights that can bring to somewhat aphysiological musculo-tendon forces.

Keywords - Musculoskeletal modeling, musculo-tendon force, joint contact force, ligament force, bone force, musculoskeletal structures interaction, static optimization, model validation 


\section{Introduction}

Many musculoskeletal structures (e.g., bones, ligaments, muscles, tendons) are solicited to perform a movement (Pandy and Andriacchi, 2010). The understanding of these structures function and the interaction between them (Cleather and Bull, 2011; Collins and O'Connor, 1991; Pandy and Andriacchi, 2010) remains a challenge that could allow in the future assisting clinicians in term of diagnosis and treatments in case of orthopaedic or neurologic disorders. In vivo measurements of musculo-tendon, joint contact, ligament and bone forces exist (Behrmann et al., 2012; Bergmann et al., 2001; Bey and Derwin, 2012; Beynnon and Fleming, 1998; D'Lima et al., 2008; Lu et al., 1998), but the protocols are invasive and inappropriate for a daily clinical use (Fleming and Beynnon, 2004). Consequently, 3D musculoskeletal modeling of the lower limb has been proposed (Al Nazer et al., 2008; Anderson and Pandy, 2001; Cleather and Bull, 2011; Crowninshield and Brand, 1981; Fraysse et al., 2009; Glitsch and Baumann, 1997; Hu et al., 2013; Lenaerts et al., 2008; Moissenet et al., 2012a; Pierrynowski and Morrison, 1985; Seireg and Arvikar, 1975; Stansfield et al., 2003; Wehner et al., 2009) as an interesting alternative and several models have been developed (Arnold et al., 2010; Delp et al., 1990; Klein Horsman et al., 2007). These models allow solving the muscular redundancy problem and estimating the forces transmitted by these musculoskeletal structures during a movement (Chèze et al., 2012; Erdemir et al., 2007). However, the validation of these models is arduous (Lund et al., 2012). Electromyographic (EMG) signals are often used to evaluate the estimated musculo-tendon forces but only provide a qualitative (Dumas et al., 2012; Modenese et al., 2011; Neptune et al., 2001; Selk Ghafari et al., 2009; Stansfield et al., 2003; Thelen and Anderson, 2006) or semi-quantitative validation (Giroux et al., n.d.; Kaufman et al., 1991; Prilutsky and Zatsiorsky, 2002). An alternative is to collect joint contact forces using instrumented prostheses (Bergmann et al., 2001; Brand et al., 1994; D'Lima et al., 2008; Lin et al., 2010; Stansfield et al., 2003). Indeed, since musculo-tendon forces have a primary role in the joint contact force generation (Herzog et al., 2003), a pertinent estimation of joint contact forces 
should be a reflection of the quality of the estimated musculo-tendon forces and consequently it should provide a quantitative validation metric for the validation of musculoskeletal models (Lund et al., 2012).

In such a context, it is necessary to ensure a good interaction between musculoskeletal structures in the model in order to assess the quality of the estimated musculo-tendon forces from the joint contact forces data. However, studies are often based on a traditional two-step method (Chèze et al., 2012; Erdemir et al., 2007). First, the musculo-tendon forces are computed using a static optimization procedure and, second, the joint reaction forces (i.e., joint contact and ligament forces) are deduced from the dynamics equation using the optimal muscular solution. Even if this method complies with the forces equilibrium, it does not allow studying the musculoskeletal structures interaction in establishing this equilibrium (Cleather and Bull, 2011). Based on this observation, Lin et al. (Lin et al., 2010) proposed an optimization procedure estimating simultaneously musculo-tendon and joint contact forces using a deformable model of the knee. However, ligaments were omitted and the study was limited to the knee joint that may bring a negative impact on the bi-articular musculo-tendon forces estimation (Fraysse et al., 2009). Optimization based methods computing simultaneously musculo-tendon, joint contact and knee ligaments forces have also been proposed recently (Cleather and Bull, 2011; Hu et al., 2013). However, the estimated forces were not validated.

The first aim of this study is to propose a 3D lower limb musculoskeletal model based on a one-step static optimization procedure allowing simultaneous musculo-tendon, joint contact, ligament and bone forces estimation during normal gait. It is postulated that this approach, by giving access to the forces transmitted by these musculoskeletal structures at both hip, tibiofemoral, patellofemoral and ankle joints, modeled using anatomically consistent kinematic models (Di Gregorio et al., 2007; Feikes et al., 2003; Sancisi and Parenti-Castelli, 2011a), should ease the validation of the model using joint contact forces measured with instrumented prostheses. The second aim is to perform a blinded model validation based on 
the datasets provided for the "Grand Challenge Competition to Predict in Vivo Knee Loads" organized by Fregly et al. (Fregly et al., 2012).

\section{Material and methods}

\section{D lower limb musculoskeletal model}

A previously described (Dumas et al., 2012; Moissenet et al., 2012a) 3D lower limb musculoskeletal model, consisting of pelvis, thigh, shank and foot segments and 43 muscular lines of action, was extended by adding the patella to perform this study (Fig. 1). Hip, tibiofemoral, patellofemoral and ankle joint kinematic models are all based on anatomical considerations (Fig. 1). Hip joint is modeled by a spherical joint. Tibiofemoral joint is modeled by a parallel mechanism made of 2 sphere-on-plane contacts (i.e., medial and lateral) and 3 isometric ligaments (i.e., anterior cruciate ligament $-\mathrm{ACL}$, posterior cruciate ligament $-\mathrm{PCL}$ and medial collateral ligament $-\mathrm{MCL}$ ) (Feikes et al., 2003). The choice of these ligament combination was made for kinematic reasons in order to ensure a 1-DOF model (Ottoboni et al., 2010; Sancisi and Parenti-Castelli, 2011b). Patellofemoral joint is modeled by a hinge joint between the patella and the femur and an isometric ligament (i.e., the patellar ligament - PT) between the patella and the tibia (Sancisi and Parenti-Castelli, 2011a). Ankle joint is modeled by a parallel mechanism made of a spherical joint and 2 isometric ligaments (between tibia and calcaneus - TiCaL and between fibula and calcaneus - CaFiL) (Di Gregorio et al., 2007). In the same way as for the tibiofemoral joint, this ligament combination is the one that most fittingly models the joint movement. Then, in order to compute muscular lever arms, a widely-used generic musculoskeletal geometric model (Delp et al., 1990) was adapted to our model (Fig. 1). 


\section{Computation framework}

First, each segment position is defined using generalized coordinates (Dumas and Chèze, 2007) that consist, for each segment $i$, in two position vectors (i.e., the proximal $P_{i}$ and distal $D_{i}$ joint centers) and two unitary direction vectors (i.e., $\mathbf{u}_{i}$ and $\mathbf{w}_{i}$ ) (Fig. 1):

$\mathbf{Q}_{i}=\left[\begin{array}{llll}\mathbf{u}_{i} & \mathbf{r}_{P_{i}} & \mathbf{r}_{D_{i}} & \mathbf{w}_{i}\end{array}\right]^{T}$

These parameters correspond to a classic set of natural coordinates (Garcia de Jalon and Bayo, 1994). Details of the segment parameters can be found in (Dumas and Chèze, 2007).

Second, the kinematic constraints $\boldsymbol{\Phi}^{k}$ and the associated Jacobian matrix $\mathbf{K}^{k}$ are defined for each joint. Since 12 parameters represent the 6 degrees-of-freedom of each segment, rigid body constraints $\boldsymbol{\Phi}^{r}$ have to be considered in addition to the kinematic constraints with the associated Jacobian matrix $\mathbf{K}^{r}$ (Duprey et al., 2010).

Third, a constrained multi-body optimization (Duprey et al., 2010; Moissenet et al., 2012a) is performed in order to obtain consistent segments positions $\mathbf{Q}$, velocities $\dot{\mathbf{Q}}$ and accelerations $\ddot{\mathbf{Q}}$.

Fourth, the full dynamics equation of the lower limb is written. In contrast with the classical approach, the dynamics equation of the whole kinematic chain is used here (Pennestrì et al., 2007), introducing the musculo-tendon forces and the Lagrange multipliers instead of motor joint moments (Dumas et al., 2012; Moissenet et al., 2012a):

$\mathbf{G} \ddot{\mathbf{Q}}+\mathbf{K}^{T} \lambda=\mathbf{E}+\mathbf{L f}$

where $\mathbf{G}$ is the generalized mass matrix, $\ddot{\mathbf{Q}}$ the consistent generalized accelerations, $\mathbf{K}=\left[\begin{array}{ll}\mathbf{K}^{k} & \mathbf{K}^{r}\end{array}\right]$ the Jacobian matrix of both joint kinematic and rigid body constraints, $\boldsymbol{\lambda}$ the Lagrange multipliers, $\mathbf{E}$ the external forces, including both weight and ground reaction forces and moments, $\mathbf{L}$ the generalized muscular lever arms and $\mathbf{f}$ the musculo-tendon forces. 
Fifth, equation 2 gives a direct access to the unknowns only composed of the musculotendon forces and the Lagrange multipliers corresponding straightforwardly to the joint contact, ligament and bone forces (Moissenet et al., 2012a). At this level, the traditional twostep method can be used (Moissenet et al., 2012a) when a parameter reduction (Garcia de Jalon and Bayo, 1994) is introduced. This parameter reduction means that all the Lagrange multipliers can be removed from equation 2. However, a selection of Lagrange multipliers can also be introduced in the objective function with the partial parameter reduction described below.

Partial parameter reduction and one-step optimization

The following linear system can be obtained from the dynamics equation 2 :

$$
\left[\begin{array}{lll}
\mathbf{L} & -\mathbf{K}_{1}^{T} & -\mathbf{K}_{2}^{T}
\end{array}\right]\left[\begin{array}{c}
\mathbf{f} \\
\boldsymbol{\lambda}_{1} \\
\boldsymbol{\lambda}_{2}
\end{array}\right]=\mathbf{G} \ddot{\mathbf{Q}}-\mathbf{E}
$$

where $\lambda_{1}$ are the Lagrange multipliers that we want to introduce in the objective function, $\lambda_{2}$ all the other ones, $\mathbf{K}_{1}$ and $\mathbf{K}_{2}$ the associated Jacobian matrices. The second group of Lagrange multipliers $\lambda_{2}$ can be cancelled from equation 3 by projecting the system on the kernel of $\mathbf{K}_{2}$, using the projection matrix $\mathbf{Z}_{\mathbf{K}_{2}}$ :

$$
\begin{aligned}
& \mathbf{Z}_{\mathbf{K}_{2}}{ }^{T} \mathbf{L} \mathbf{f}-\mathbf{Z}_{\mathbf{K}_{2}}{ }^{T} \mathbf{K}_{1}{ }_{1}^{T} \boldsymbol{\lambda}_{1}-\mathbf{Z}_{\mathbf{K}_{2}}{ }^{T} \mathbf{K}_{2}{ }^{T} \boldsymbol{\lambda}_{2}=\mathbf{Z}_{\mathbf{K}_{2}}{ }^{T}(\mathbf{G} \ddot{\mathbf{Q}}-\mathbf{E}) \\
& \Leftrightarrow \mathbf{Z}_{\mathbf{K}_{2}}{ }^{T} \mathbf{L} \mathbf{f}-\mathbf{Z}_{\mathbf{K}_{2}}{ }^{T} \mathbf{K}_{1}{ }^{T} \boldsymbol{\lambda}_{1}=\mathbf{Z}_{\mathbf{K}_{2}}{ }^{T}(\mathbf{G} \mathbf{Q}-\mathbf{E}) \\
& \Leftrightarrow \mathbf{Z}_{\mathbf{K}_{2}}^{T}\left[\begin{array}{ll}
\mathbf{L} & -\mathbf{K}_{1}^{T}
\end{array}\right]\left[\begin{array}{c}
\mathbf{f} \\
\boldsymbol{\lambda}_{1}
\end{array}\right]=\mathbf{Z}_{\mathbf{K}_{2}}{ }^{T}(\mathbf{G} \mathbf{Q}-\mathbf{E})
\end{aligned}
$$

where $\mathbf{Z}_{\mathbf{K}_{2}}$ is a matrix composed of the eigenvectors of the square matrix $\mathbf{K}_{2}{ }^{T} \mathbf{K}_{2}$ corresponding to the null eigenvalues. If necessary, Lagrange multipliers $\lambda_{2}$ can be computed a posteriori using the optimal solution $\left[\begin{array}{ll}\mathbf{f} & \lambda_{1}\end{array}\right]^{T}$ (Moissenet et al., 2012a). 
The unknowns $\left[\begin{array}{ll}\mathbf{f} & \lambda_{1}\end{array}\right]^{T}$, corresponding respectively to the musculo-tendon forces and the selected joint contact, ligament and bone forces, are then introduced in a one-step optimization procedure in order to solve the muscular redundancy problem. A typical static optimization procedure is used and defined as follow (Dumas et al., 2012; Moissenet et al., 2012a, 2012b):

$$
\begin{gathered}
\min _{\left[\begin{array}{l}
\mathbf{f} \\
\lambda_{1}
\end{array}\right]} J=\frac{1}{2}\left[\begin{array}{c}
\mathbf{f} \\
\boldsymbol{\lambda}_{1}
\end{array}\right]^{T} \mathbf{W}\left[\begin{array}{c}
\mathbf{f} \\
\boldsymbol{\lambda}_{1}
\end{array}\right] \\
\text { constraint to : }\left\{\begin{array}{c}
\mathbf{Z}_{\mathbf{K}_{2}}{ }^{T}\left[\begin{array}{ll}
\mathbf{L} & -\mathbf{K}_{1}{ }^{T}
\end{array}\right]\left[\begin{array}{c}
\mathbf{f} \\
\boldsymbol{\lambda}_{1}
\end{array}\right]=\mathbf{Z}_{\mathbf{K}_{2}}{ }^{T}(\mathbf{G} \ddot{\mathbf{Q}}-\mathbf{E}) \\
{\left[\begin{array}{c}
\mathbf{f} \\
\boldsymbol{\lambda}_{1}
\end{array}\right] \geq \mathbf{0}}
\end{array}\right.
\end{gathered}
$$

where $J$ is the objective function and $\mathbf{W}$ a diagonal matrix composed of the optimization weights associated to the unknowns $\left[\begin{array}{ll}\mathbf{f} & \lambda_{1}\end{array}\right]^{T}$. When an optimization weight is not null, the associated force is minimized and constrained to be positive. Otherwise, when the optimization weight is null, the associated force is only constrained to be positive. The optimization weights used for this study are described below.

\section{Experimental dataset and estimations}

In order to perform the blinded validation of this model, a set of estimations was performed based on the datasets provided for the "Grand Challenge Competition to Predict in Vivo Knee Loads" (Fregly et al., 2012). We present here the mean results for 5 normal gait cycles for each of the four last competitions (subject1: male/166cm/64.6kg, subject2: male/172cm $/ 67 \mathrm{~kg}$, subject3: female $/ 167 \mathrm{~cm} / 78.4 \mathrm{~kg}$, subject4: male $/ 168 \mathrm{~cm} / 66.7 \mathrm{~kg}$ ). All subjects have the particularity to have an instrumented knee prosthesis that allows comparing the estimated and the measured medial and lateral knee contact forces during the gait cycle. A full description of the datasets is provided by Fregly et al. (Fregly et al., 2012). 
The RMS values of the recorded EMG signals were processed within a window of 25ms (De Luca, 1997) to obtain the EMG envelopes.

Regarding the number of parameters to be minimized (i.e., musculo-tendon, joint contact, ligament and bone forces), many combinations of optimization weights are possible. In order to illustrate the impact of the optimization weights, two minimization conditions were performed for each gait cycle of each subject. Condition 1 (i.e., C1) stands for the traditional optimization strategy where only musculo-tendon forces are minimized. Under condition 2 (i.e., C2), all the musculo-tendon forces and Lagrange multipliers $\lambda_{1}$ are minimized while focusing more specifically on tibiofemoral joint contact forces since these forces are usually overestimated (Fregly et al., 2012; Gerus et al., 2013). The optimization weights chosen for each condition are given in Table 1.

\section{Blinded model validation}

A blinded validation was performed in order to evaluate the model's ability to estimate musculo-tendon, joint contact and bone forces during normal gait.

First, the estimated musculo-tendon forces were compared to the subject's EMG envelopes using the coefficient of concordance proposed by Dickerson et al. (Dickerson et al., 2008) and recently extended to the gait analysis by Giroux et al. (Giroux et al., n.d.). Briefly, this method uses active/inactive state concordance between the estimated musculotendon forces and the EMG envelopes to compute a coefficient of concordance defined as the percentage of concordance elements. For this study, muscles were defined active when the mean value was above 20 percent of the maximum of the estimated musculo-tendon force and of the EMG envelope, respectively (Pedersen et al., 1987) during each of the 7 gait phases (Perry and Burnfield, 1992) (Fig. 2 \& 5). A set of published EMG envelopes (Perry and Burnfield, 1992) was processed similarly (Fig. 2 \& 5) and stands for an asymptomatic active/inactive state reference. This method allows a semi-quantitative validation regarding 
the model's ability to estimate musculo-tendon forces in concordance with the subject's EMG envelopes and with asymptomatic reference as in previous studies (Modenese et al., 2011; Stansfield et al., 2003).

Second, the estimated tibiofemoral contact forces (i.e., medial and lateral contact forces) were compared to the measured tibiofemoral contact forces. For this, first and second force peaks root mean square error (i.e., RMSE) and correlation coefficient (i.e., $\mathrm{R}^{2}$ ) were computed. This method allows a quantitative validation regarding the model's ability to estimate tibiofemoral joint contacts forces.

Third, the estimated hip contact and femur axial forces were compared qualitatively to measured data of the literature.

Only a selection of musculo-tendon, joint contact, ligament and bone forces are reported in the results. The most important muscles during gait were kept and the muscles having similar activities (e.g., vastus medialis and vastus lateralis) were removed. Moreover, only the joint contact and bone forces for which in vivo measurements are available are presented. For illustrative purpose, $\mathrm{ACL}$ and PCL forces are also reported. Additional results are available in the Supplementary material.

\section{Results}

Under the condition $\mathrm{C} 1$, the estimated musculo-tendon forces patterns are in a good agreement with most of the subject's or the asymptomatic active/inactive states (Fig. 2). This observation is confirmed by substantial coefficients of concordance (Table 2). However, abnormal forces appear on gastrocnemius medialis during phase 1 (i.e., loading response) and on gluteus maximus during phase 4 and 5 (i.e., pre-swing and initial swing). Vastus medialis shows an abnormal force during all the stance phase. It also shows abnormal peaks of force during phases 4 and 5 unlike the asymptomatic inactive state, but like the active state of subjects 1,3 and 4 . Rectus femoris shows a force during almost the whole stance 
phase. The estimated tibiofemoral forces present a good correlation with implant measurements (Table 2: $0.6588 \leq \mathrm{R}^{2} \leq 0.9040$ ) but are overestimated (Table 2: $0.4356 \mathrm{BW} \leq \mathrm{RMSE} \leq 1.3931 \mathrm{BW}$ ) with high errors at the second peak of force (Table 2: $1.1052 \mathrm{BW} \leq$ Peak2 $\leq 3.6722 \mathrm{BW})$. On the whole, the estimated medial and lateral tibiofemoral contact forces have a similar pattern and amplitude with a second peak of force higher than the first one (Fig. 3). The estimated hip contact and femur axial forces present similarities with literature measurements (Lu et al., 1998; Stansfield et al., 2003). But again, these forces are overestimated. Roughly, $A C L$ and $P C L$ forces produce one or two peaks of force under 2 BW (Fig. 4).

Under the condition C2, the tibiofemoral contact forces are strongly improved (Table 2: $0.2187 \mathrm{BW} \leq \mathrm{RMSE} \leq 0.4981 \mathrm{BW}$ ) with lower errors at the second peak of force (Table 2: $0.0775 \mathrm{BW} \leq$ Peak2 $\leq 1.1144 \mathrm{BW})$. The correlation with implant measurements remains unchanged (Table 2: $0.6599 \leq \mathrm{R}^{2} \leq 0.8896$ ). The amplitudes of the hip contact force and femur axial forces are reduced and in better agreement with the literature values. However, the coefficients of concordance of estimated musculo-tendon forces are decreased (Table 2). This is illustrated, in most of the cases, by the aphysiological extinction of the semimembranosus and gastrocnemius medialis during stance phase, and by a decreased force of the tibialis anterior during swing phase. It is interesting to observe that the decrease of the gastrocnemii force is compensated by a force increase of the soleus. Nevertheless, the vastus medialis force is decreased during stance phase since it only remains force peaks at phases 1 and 4. Roughly, ACL and PCL forces patterns still present one or two peaks of force but their amplitude is decreased and is now under 1 BW (Fig. 7). 


\section{Discussion}

3D musculoskeletal modeling is opening new possibilities in terms of movement simulation and understanding of the interaction between the underlying structures (e.g., bones, ligaments, muscles, tendons). Moreover, the use of instrumented prostheses now offers a unique chance to validate the models in terms of forces estimation during a movement. For example, some datasets have been recently made available (Fregly et al., 2012) to evaluate models during gait (Hast and Piazza, 2013; Lundberg et al., 2013; Manal and Buchanan, 2013). This has motivated us to validate our model using these datasets.

Our first goal was to present our 3D lower limb musculoskeletal model. This model, previously described by Dumas et al. (Dumas et al., 2012) and Moissenet et al. (Moissenet et al., 2012a, 2012b), was updated by introducing the patella segment. A description of this model was given to allow a good understanding of its composition. More details and discussions can be found in the previous publications (Dumas et al., 2012; Duprey et al., 2010; Moissenet et al., 2012a, 2012b). This model enables studying musculo-tendon, detailed joint contact, ligament and bone forces at hip, tibiofemoral, patellofemoral and ankle joints during gait thanks to an underlying computation framework based on the partial parameter reduction method, introducing a selection of Lagrange multipliers (i.e., joint contact, ligament and bone forces) in the optimization procedure. This method enables defining a large range of optimization criteria for potential future clinical applications. The second optimization condition presented here shows that the estimation is closer to the implant measurements when joint contact forces, and more specifically tibiofemoral contact forces, are minimized. However, when these forces are introduced in the optimization procedure, some aphysiological results can arise, such as the extinction of the gastrocnemius medialis and semimembranosus during the stance phase. Such result was also reported on the gastrocnemii when simulating gait (Lin et al., 2010) and when testing different objective functions during a vertical jumping simulation (Cleather and Bull, 2011). Similarly, Modenese et al. (Modenese et al., 2011) have compared, for gait and stair 
climbing, the minimization of the musculo-tendon forces using different powers in the objective function. They show that the use of a unitary power provided aphysiological musculo-tendon forces compared to EMG envelopes, but hip contact force was in better agreement with in vivo measurements. All these results highlight an important limit of the current musculoskeletal models and methods since it remains difficult to define an objective function (e.g., minimization of the musculo-tendon forces appended with joint reactions forces or not, with a power one or more), that provides simultaneously physiological musculo-tendon forces and valid joint contact forces.

The second goal of this study was to perform a blinded model validation. A semiquantitative validation of the estimated musculo-tendon forces and a quantitative validation of the estimated tibiofemoral joint contacts forces were completed by a qualitative evaluation of hip contact force and femur axial force. On the one hand, the results show that the model is able to estimate in most cases the correct pattern and timing of these forces, but the force amplitude is highly influenced by the optimization weights. On the whole, the coefficients of active/inactive state concordance obtained when comparing to the subject's EMG envelopes or the asymptomatic EMG envelopes (Perry and Burnfield, 1992) were similar in terms of value. Specifically, the estimated rectus femoris forces, under condition C1, show a peak of force during terminal stance and preswing. These results, already reported by Modenese et al. (Modenese et al., 2011), are in contrast with the subject's EMG envelopes, but in accordance with those reported by Perry and Burnfield (Perry and Burnfield, 1992). It shows that, since our model, in its current state, should only be used for asymptomatic subjects, the timing of onset of estimated musculo-tendon forces can differ to the onset of EMG of a subject presenting a gait disorder. In other words, when the subject's EMG envelopes highly differ from the asymptomatic ones, the quality of musculo-tendon forces estimation seems degrade. With that respect, only methods that quantitatively include EMG data in the optimization process (Gerus et al., 2013; Manal and Buchanan, 2013) seem able to deal with such issue. On the other hand, the second optimization condition shows that the model is potentially able to well estimate medial and lateral tibiofemoral joint contacts forces during 
normal gait. Moreover, the lateral tibiofemoral compartment remains loaded during most of the stance phase, as recorded by the implant, instead of previously reported results (Moissenet et al., 2012a; Shelburne et al., 2006). Finally, the results suggest that the musculoskeletal system, in order to minimize tibiofemoral joint contacts forces, tries first to reduce the vastii, gastrocnemii and hamstrings forces during stance. This observation is consistent with the repartition of the musculo-tendon forces contribution to the tibiofemoral joint contacts forces previously described (Pandy and Andriacchi, 2010; Sritharan et al., 2012). Indeed, it has been reported that these muscles have the highest contribution to the resultant tibiofemoral contacts forces. However, it results in aphysiological musculo-tendon forces.

Even if our model provides new opportunities for musculoskeletal estimations, this study still possesses a number of limitations. First, the model is based on different scaled generic models and so do not represent the real geometry of the subjects. It is well known that musculoskeletal geometry affects the forces computation (Bonnefoy et al., 2009; Carbone et al., 2012; Cleather and Bull, 2011) and that a solution is to combine medical imaging techniques with musculoskeletal modeling to improve accuracy of the models (Arnold et al., 2000; Scheys, 2005). Even if the present study uses basically generic models, it should be noted that the joint kinematic models used for tibiofemoral, patellofemoral and ankle joints may be easily adjusted to the patient's geometry using medical imaging. Second, the use of an inverse dynamics based optimization procedure can bring perturbation as input of the model with the well-known soft tissue artifacts. The results show that artifacts can appear on musculo-tendon, joint contact and bone forces (Figs. 2-7) at heel strike and toe off events. Third, the use of parallel mechanisms models for gait simulations can be discussed. Indeed, these models have been developed based on in vitro unloaded knee movements and consider ligaments as isometric structures. However, it has been shown that the kinematics of tibiofemoral and patellofemoral joints are similar between loaded and unloaded conditions during knee extension (Lu et al., 2008) and that the ligament lengthening is limited during gait (Liu et al., 2011; Wu et al., 2010). Nevertheless, the isometric condition would have 
brought to pushing ligaments (i.e., negative force) if the associated Lagrange multiplier have not been introduced in the optimization procedure. This issue has been previously reported for the MCL force (Moissenet et al., 2012a) and can be avoided by introducing deformable ligaments in our model (Gasparutto et al., 2012). Fourth, the choice of the musculoskeletal geometric model may have a significant impact on the results. Indeed, the current model is only composed of 43 muscular lines of action (Delp et al., 1990) that may not be enough to describe accurately the mechanical effect of the muscles (Valente et al., 2012; Van der Helm and Veenbaas, 1991). Models with additional muscular lines of action exist (Klein Horsman et al., 2007) and may enlarge the optimization solution space. Last but not least, the optimization weights were chosen in order to illustrate two specific strategies. As discussed previously, they can have positive and negative impacts on the results. In the literature, the inverse of squared average cross-sectional area of the muscles is classically used, but other coefficients should also be introduced in order to modulate the minimization of each group of force (i.e., musculo-tendon, joint contact, ligament and bone forces). Up to now, such weighting has been arbitrary assigned (Cleather and Bull, 2011; Hu et al., 2013; Lin et al., 2010; Raikova, 2009). However, because it could be an image of the motor control strategy, the question of relative weights in the objective function should be investigated in the future. For example, it should be possible to determine some optimal weights by using a two-level optimization (Mombaur et al., 2009).

To conclude, our 3D lower limb musculoskeletal model is versatile, in the sense that generic models implemented can be personalized and that it allows infinite optimization criteria to model motor control strategies and interactions between underlying structures (e.g., bones, ligaments, muscles, tendons). Moreover, the blinded model validation shows the potential of this model to estimate both and simultaneously musculo-tendon, joint contact and bone forces during normal gait. This demonstrates the value of the modeling and computation framework proposed in this study. However some limitations remain and the selection of optimization weights will be a huge challenge for the further development of our model. 


\section{Acknowledgements}

The authors gratefully acknowledge Edouard Jouan and Matthieu Giroux (MSc) for their involvement and their work in this project during their master thesis.

\section{Conflict of interest}

The authors do not have any financial or personal relationship with other people or organization that could inappropriately influence their work.

\section{References}

Al Nazer, R., Rantalainen, T., Heinonen, A., Sievänen, H., Mikkola, A., 2008. Flexible multibody simulation approach in the analysis of tibial strain during walking. Journal of biomechanics 41, 1036-43.

Anderson, F.C., Pandy, M.G., 2001. Dynamic optimization of human walking. Journal of biomechanical engineering 123, 381-90.

Arnold, A.S., Salinas, S., Asakawa, D.J., Delp, S.L., 2000. Accuracy of muscle moment arms estimated from MRI-based musculoskeletal models of the lower extremity. Computer aided surgery : official journal of the International Society for Computer Aided Surgery 5, 108-19.

Arnold, E.M., Ward, S.R., Lieber, R.L., Delp, S.L., 2010. A model of the lower limb for analysis of human movement. Annals of biomedical engineering 38, 269-79.

Behrmann, G.P., Hidler, J., Mirotznik, M.S., 2012. Fiber optic micro sensor for the measurement of tendon forces. Biomedical engineering online 11, 77.

Bergmann, G., Deuretzbacher, G., Heller, M., Graichen, F., Rohlmann, A., Strauss, J., Duda, G.N., 2001. Hip contact forces and gait patterns from routine activities. Journal of biomechanics 34, 859-71.

Bey, M.J., Derwin, K.A., 2012. Measurement of in vivo tendon function. Journal of shoulder and elbow surgery / American Shoulder and Elbow Surgeons ... [et al.] 21, 149-57.

Beynnon, B.D., Fleming, B.C., 1998. Anterior cruciate ligament strain in-vivo: a review of previous work. Journal of biomechanics 31, 519-25. 
Bonnefoy, A., Pradon, D., Dumas, R., Chèze, L., 2009. Influence of the moment arms on the quadriceps muscular force of the knee during the stance phase of the gait. Series on Biomechanics 24, 33-43.

Brand, R.A., Pedersen, D.R., Davy, D.T., Kotzar, G.M., Heiple, K.G., Goldberg, V.M., 1994. Comparison of hip force calculations and measurements in the same patient. The Journal of arthroplasty $9,45-51$.

Carbone, V., Van der Krogt, M.M., Koopman, H.F.J.M., Verdonschot, N., 2012. Sensitivity of subject-specific models to errors in musculo-skeletal geometry. Journal of biomechanics 45, 2476-80.

Chèze, L., Moissenet, F., Dumas, R., 2012. State of the art and current limits of musculoskeletal models for clinical applications. Movement \& Sport Sciences - Science \& Motricité.

Cleather, D.J., Bull, A.M.J., 2011. An optimization-based simultaneous approach to the determination of muscular, ligamentous, and joint contact forces provides insight into musculoligamentous interaction. Annals of biomedical engineering 39, 1925-34.

Collins, J.J., O'Connor, J.J., 1991. Muscle-ligament interactions at the knee during walking. Proceedings of the Institution of Mechanical Engineers. Part $\mathrm{H}$, Journal of engineering in medicine 205, 11-8.

Crowninshield, R.D., Brand, R.A., 1981. A physiologically based criterion of muscle force prediction in locomotion. Journal of biomechanics 14, 793-801.

De Luca, C., 1997. The use of surface electromyography in biomechanics. Journal of Applied Biomechanics 13, $135-163$.

Delp, S.L., Loan, J.P., Hoy, M.G., Zajac, F.E., Topp, E.L., Rosen, J.M., 1990. An interactive graphics-based model of the lower extremity to study orthopaedic surgical procedures. IEEE transactions on bio-medical engineering 37, 757-67.

Di Gregorio, R., Parenti-Castelli, V., O'Connor, J.J., Leardini, A., 2007. Mathematical models of passive motion at the human ankle joint by equivalent spatial parallel mechanisms. Medical \& biological engineering \& computing 45, 305-13.

Dickerson, C.R., Hughes, R.E., Chaffin, D.B., 2008. Experimental evaluation of a computational shoulder musculoskeletal model. Clinical biomechanics (Bristol, Avon) 23, 886-94.

Dumas, R., Chèze, L., 2007. 3D inverse dynamics in non-orthonormal segment coordinate system. Medical \& biological engineering \& computing 45, 315-22.

Dumas, R., Moissenet, F., Gasparutto, X., Cheze, L., 2012. Influence of joint models on lower-limb musculo-tendon forces and three-dimensional joint reaction forces during gait. Proceedings of the Institution of Mechanical Engineers. Part $\mathrm{H}$, Journal of engineering in medicine 226, 146-60.

Duprey, S., Cheze, L., Dumas, R., 2010. Influence of joint constraints on lower limb kinematics estimation from skin markers using global optimization. Journal of biomechanics 43, 2858-62. 
D'Lima, D.D., Steklov, N., Fregly, B.J., Banks, S.A., Colwell, C.W., 2008. In vivo contact stresses during activities of daily living after knee arthroplasty. Journal of orthopaedic research : official publication of the Orthopaedic Research Society 26, 1549-55.

Erdemir, A., McLean, S., Herzog, W., Van den Bogert, A.J., 2007. Model-based estimation of muscle forces exerted during movements. Clinical biomechanics (Bristol, Avon) 22, 131-54.

Feikes, J.D., O'Connor, J.J., Zavatsky, A.B., 2003. A constraint-based approach to modelling the mobility of the human knee joint. Journal of biomechanics 36, 125-9.

Fleming, B.C., Beynnon, B.D., 2004. In vivo measurement of ligament/tendon strains and forces: a review. Annals of biomedical engineering 32, 318-28.

Fraysse, F., Dumas, R., Cheze, L., Wang, X., 2009. Comparison of global and joint-to-joint methods for estimating the hip joint load and the muscle forces during walking. Journal of biomechanics 42, 2357-62.

Fregly, B.J., Besier, T.F., Lloyd, D.G., Delp, S.L., Banks, S.A., Pandy, M.G., D'Lima, D.D., 2012. Grand challenge competition to predict in vivo knee loads. Journal of orthopaedic research : official publication of the Orthopaedic Research Society 30, 503-13.

Garcia de Jalon, J., Bayo, E., 1994. Kinematic and dynamic simulation of multibody systems. The real-time challenge. Springer-Verlag, New-York.

Gasparutto, X., Dumas, R., Jacquelin, E., 2012. Multi-body optimisation with deformable ligament constraints: influence of ligament geometry. Computer Methods in Biomechanics and Biomedical Engineering 15 Suppl 1, 191-3.

Gerus, P., Sartori, M., Besier, T.F., Fregly, B.J., Delp, S.L., Banks, S.A., Pandy, M.G., D'Lima, D.D., Lloyd, D.G., 2013. Subject-specific knee joint geometry improves predictions of medial tibiofemoral contact forces. Journal of Biomechanics.

Giroux, M., Moissenet, F., Dumas, R., n.d. EMG-based validation of musculo-skeletal models for gait analysis. Computer Methods in Biomechanics and Biomedical Engineering.

Glitsch, U., Baumann, W., 1997. The three-dimensional determination of internal loads in the lower extremity. Journal of biomechanics 30, 1123-31.

Hast, M.W., Piazza, S.J., 2013. Dual-joint modeling for estimation of total knee replacement contact forces during locomotion. Journal of biomechanical engineering 135, 021013.

Herzog, W., Longino, D., Clark, A., 2003. The role of muscles in joint adaptation and degeneration. Langenbeck's archives of surgery / Deutsche Gesellschaft für Chirurgie 388, 305-15.

Hu, C.-C., Lu, T.-W., Chen, S.-C., 2013. Influence of model complexity and problem formulation on the forces in the knee calculated using optimization methods. Biomedical engineering online 12, 20.

Kaufman, K.R., An, K.N., Litchy, W.J., Chao, E.Y., 1991. Physiological prediction of muscle forces--II. Application to isokinetic exercise. Neuroscience 40, 793-804. 
Klein Horsman, M.D., Koopman, H.F.J.M., Van der Helm, F.C.T., Prosé, L.P., Veeger, H.E.J., 2007. Morphological muscle and joint parameters for musculoskeletal modelling of the lower extremity. Clinical biomechanics (Bristol, Avon) 22, 239-47.

Lenaerts, G., De Groote, F., Demeulenaere, B., Mulier, M., Van der Perre, G., Spaepen, A., Jonkers, I., 2008. Subject-specific hip geometry affects predicted hip joint contact forces during gait. Journal of biomechanics $41,1243-52$.

Lin, Y.-C., Walter, J.P., Banks, S.A., Pandy, M.G., Fregly, B.J., 2010. Simultaneous prediction of muscle and contact forces in the knee during gait. Journal of biomechanics $43,945-52$.

Liu, F., Gadikota, H.R., Kozánek, M., Hosseini, A., Yue, B., Gill, T.J., Rubash, H.E., Li, G., 2011. In vivo length patterns of the medial collateral ligament during the stance phase of gait. Knee surgery, sports traumatology, arthroscopy : official journal of the ESSKA 19, 719-27.

Lu, T.-W., Tsai, T.-Y., Kuo, M.-Y., Hsu, H.-C., Chen, H.-L., 2008. In vivo three-dimensional kinematics of the normal knee during active extension under unloaded and loaded conditions using single-plane fluoroscopy. Medical Engineering \& Physics 30, 1004 1012.

Lu, T.W., O'Connor, J.J., Taylor, S.J., Walker, P.S., 1998. Validation of a lower limb model with in vivo femoral forces telemetered from two subjects. Journal of biomechanics 31 , 63-9.

Lund, M.E., De Zee, M., Andersen, M.S., Rasmussen, J., 2012. On validation of multibody musculoskeletal models. Proceedings of the Institution of Mechanical Engineers. Part $\mathrm{H}$, Journal of engineering in medicine 226, 82-94.

Lundberg, H.J., Knowlton, C., Wimmer, M.A., 2013. Fine tuning total knee replacement contact force prediction algorithms using blinded model validation. Journal of biomechanical engineering 135, 021015.

Manal, K., Buchanan, T.S., 2013. An electromyogram-driven musculoskeletal model of the knee to predict in vivo joint contact forces during normal and novel gait patterns. Journal of biomechanical engineering 135, 021014.

Modenese, L., Phillips, A.T.M., Bull, A.M.J., 2011. An open source lower limb model: Hip joint validation. Journal of biomechanics 44, 2185-93.

Moissenet, F., Chèze, L., Dumas, R., 2012a. Anatomical kinematic constraints: consequences on musculo-tendon forces and joint reactions. Multibody System Dynamics 28, 125-141.

Moissenet, F., Chèze, L., Dumas, R., 2012b. Potential of the pseudo-inverse method as a constrained static optimization for musculo-tendon forces prediction. Journal of biomechanical engineering 134, 064503.

Mombaur, K., Truong, A., Laumond, J.-P., 2009. From human to humanoid locomotion-an inverse optimal control approach. Autonomous Robots 28, 369-383. 
Neptune, R.R., Kautz, S.A., Zajac, F.E., 2001. Contributions of the individual ankle plantar flexors to support, forward progression and swing initiation during walking. Journal of biomechanics 34, 1387-98.

Ottoboni, A., Parenti-Castelli, V., Sancisi, N., Belvedere, C., Leardini, A., 2010. Articular surface approximation in equivalent spatial parallel mechanism models of the human knee joint: an experiment-based assessment. Proceedings of the Institution of Mechanical Engineers. Part H, Journal of engineering in medicine 224, 1121-32.

Pandy, M.G., Andriacchi, T.P., 2010. Muscle and joint function in human locomotion. Annual review of biomedical engineering 12, 401-33.

Pedersen, D.R., Brand, R.A., Cheng, C., Arora, J.S., 1987. Direct comparison of muscle force predictions using linear and nonlinear programming. Journal of Biomechanical Engineering 109, 192-199.

Pennestrì, E., Stefanelli, R., Valentini, P.P., Vita, L., 2007. Virtual musculo-skeletal model for the biomechanical analysis of the upper limb. Journal of biomechanics 40, 1350-61.

Perry, D.J., Burnfield, D.J., 1992. Gait Analysis: Normal and Pathological Function. SLACK Incorporated.

Pierrynowski, M.R., Morrison, J.B., 1985. A physiological model for the evaluation of muscular forces in human locomotion: theoretical aspects. Mathematical Biosciences 75, 69-101.

Prilutsky, B.I., Zatsiorsky, V.M., 2002. Optimization-based models of muscle coordination. Exercise and sport sciences reviews 30, 32-8.

Raikova, R.T., 2009. Investigation of the influence of the elbow joint reaction on the predicted muscle forces using different optimization functions. Journal of Musculoskeletal Research 12, 31-43.

Sancisi, N., Parenti-Castelli, V., 2011a. A New Kinematic Model of the Passive Motion of the Knee Inclusive of the Patella. Journal of Mechanisms and Robotics 3, 041003.

Sancisi, N., Parenti-Castelli, V., 2011b. On the role of ligaments in the guidance of the human knee passive motion. In: Proceedings of Euromech Colloquium 511, Ponta Delgada, 9-11 March.

Scheys, L., 2005. Image based methods to generate subject-specific musculoskeletal models for gait analysis. International Congress Series 1281, 62 - 67.

Seireg, A., Arvikar, 1975. The prediction of muscular lad sharing and joint forces in the lower extremities during walking. Journal of biomechanics 8, 89-102.

Selk Ghafari, A., Meghdari, A., Vossoughi, G.R., 2009. Muscle-driven forward dynamics simulation for the study of differences in muscle function during stair ascent and descent. Proceedings of the Institution of Mechanical Engineers. Part $\mathrm{H}$, Journal of engineering in medicine $223,863-74$.

Shelburne, K.B., Torry, M.R., Pandy, M.G., 2006. Contributions of muscles, ligaments, and the ground-reaction force to tibiofemoral joint loading during normal gait. Journal of 
orthopaedic research : official publication of the Orthopaedic Research Society 24, 1983-90.

Sritharan, P., Lin, Y.-C., Pandy, M.G., 2012. Muscles that do not cross the knee contribute to the knee adduction moment and tibiofemoral compartment loading during gait. Journal of orthopaedic research : official publication of the Orthopaedic Research Society 30, 1586-95.

Stansfield, B.W., Nicol, A.C., Paul, J.P., Kelly, I.G., Graichen, F., Bergmann, G., 2003. Direct comparison of calculated hip joint contact forces with those measured using instrumented implants. An evaluation of a three-dimensional mathematical model of the lower limb. Journal of biomechanics 36, 929-36.

Thelen, D.G., Anderson, F.C., 2006. Using computed muscle control to generate forward dynamic simulations of human walking from experimental data. Journal of biomechanics 39, 1107-15.

Valente, G., Martelli, S., Taddei, F., Farinella, G., Viceconti, M., 2012. Muscle discretization affects the loading transferred to bones in lower-limb musculoskeletal models.

Proceedings of the Institution of Mechanical Engineers. Part $\mathrm{H}$, Journal of engineering in medicine 226, 161-9.

Van der Helm, F.C., Veenbaas, R., 1991. Modelling the mechanical effect of muscles with large attachment sites: application to the shoulder mechanism. Journal of biomechanics 24, 1151-63.

Wehner, T., Claes, L., Simon, U., 2009. Internal loads in the human tibia during gait. Clinical biomechanics (Bristol, Avon) 24, 299-302.

Wu, J.-L., Hosseini, A., Kozanek, M., Gadikota, H.R., Gill, T.J., Li, G., 2010. Kinematics of the anterior cruciate ligament during gait. The American journal of sports medicine 38 , 1475-82. 


\section{Tables and figures captions:}

Table 1: Lagrange multipliers introduced in the objective function (i.e., $\boldsymbol{\lambda}_{1}$ ) and corresponding optimization weights for both minimization conditions.

Table 2: Descriptive statistics under condition C1 (i.e., only musculo-tendon forces are minimized) and condition C2 (i.e., musculo-tendon, joint contact, ligament and bone forces are minimized while focusing more specifically on tibiofemoral joint contacts) model estimations. The coefficient of concordance is defined as the percentage of active/inactive state concordance elements between the estimated musculo-tendon forces (i.e., m-t f.) and the measured EMG envelopes (subject and asymptomatic). Peak1 and Peak2 are the differences at first and second peak forces between the estimated tibiofemoral joint contact forces and the in vivo measurements in bodyweights. RMSE is the root mean square error over the gait cycle in bodyweights. $\mathrm{R}^{2}$ is correlation coefficient over the gait cycle.

Figure 1: Musculoskeletal model: segment parameters (Dumas and Chèze, 2007) (i.e., $\mathbf{Q}_{i}=\left[\begin{array}{llll}\mathbf{u}_{i} & \mathbf{r}_{P_{i}} & \mathbf{r}_{D_{i}} & \mathbf{w}_{i}\end{array}\right]^{T}$, all vectors expressed in the inertial coordinate system, ICS), joint kinematic constraints (Duprey et al., 2010) (i.e., joint kinematic models of hip, tibiofemoral, patellofemoral and ankle joints) and musculo-tendon geometry (Delp et al., 1990).

Figure 2: Comparison between a set of mean estimated musculo-tendon forces (i.e., gluteus maximus - Gmax, gluteus medius - Gmed, adductor magnus - Addmagnus, vastus medialis - Vasmed, vastus lateralis - Vaslat, rectus femoris - RF, semimembranosus Semimem, biceps femoris long head - Bifem, tensor fascia lata - TFL, gastrocnemius medialis - Gasmed, gastrocnemius lateralis - Gaslat, soleus - Soleus, tibialis anterior - Tibant and peroneus longus - Peronl) and the corresponding active/inactive state (i.e., from the subject and asymptomatic measured EMG envelopes) under condition C1 (i.e., only musculo-tendon forces are minimized). The results are given in bodyweights over the gait cycle for each of the subjects. Standard deviations (i.e., std) are given for the estimated 
forces. The toe off is indicated by a vertical dotted line. For additional results, please see the Supplementary material.

Figure 3: Comparison between the mean estimated joint contact and bone forces and the mean implant or mean literature measurements under condition C1 (i.e., only musculotendon forces are minimized). The results are given in bodyweights over the gait cycle for each of the subjects. Standard deviations (i.e., std) are given for the estimated forces and the implant measures. The toe off is indicated by a vertical dotted line. For additional results, please see the Supplementary material.

Figure 4: $\quad$ Mean estimated ligament forces under condition C1 (i.e., only musculo-tendon forces are minimized). The results are given in bodyweights over the gait cycle for each of the subjects. Standard deviations (i.e., std) are given for the estimated forces. The toe off is indicated by a vertical dotted line. For additional results, please see the Supplementary material.

Figure 5: Comparison between a set of mean estimated musculo-tendon forces (i.e., gluteus maximus - Gmax, gluteus medius - Gmed, adductor magnus - Addmagnus, vastus medialis - Vasmed, vastus lateralis - Vaslat, rectus femoris - RF, semimembranosus Semimem, biceps femoris long head - Bifem, tensor fascia lata - TFL, gastrocnemius medialis - Gasmed, gastrocnemius lateralis - Gaslat, soleus - Soleus, tibialis anterior - Tibant and peroneus longus - Peronl) and the corresponding recorded muscular activity (i.e., from EMG signals and from results reported by Perry and Burnfield (Perry and Burnfield, 1992)) under condition C2 (i.e., musculo-tendon, joint contact, ligament and bone forces are minimized while focusing more specifically on tibiofemoral joint contacts). The results are given in bodyweights over the gait cycle for each of the subjects. Standard deviations (i.e., std) are given for the estimated forces. The toe off is indicated by a vertical dotted line. For additional results, please see the Supplementary material.

Figure 6: Comparison between the mean estimated joint contact and bone forces and the mean implant or literature measures under condition C2 (i.e., musculo-tendon, joint contact, ligament and bone forces are minimized while focusing more specifically on 
tibiofemoral joint contacts). The results are given in bodyweights over the gait cycle for each of the subjects. Standard deviations (i.e., std) are given for the estimated forces and the implant measures. The toe off is indicated by a vertical dotted line. For additional results, please see the Supplementary material.

Figure 7: $\quad$ Mean estimated ligament forces under condition C2 (i.e., musculo-tendon, joint contact, ligament and bone forces are minimized while focusing more specifically on tibiofemoral joint contacts). The results are given in bodyweights over the gait cycle for each of the subjects. Standard deviations (i.e., std) are given for the estimated forces. The toe off is indicated by a vertical dotted line. For additional results, please see the Supplementary material. 
Table 1:

\begin{tabular}{cccc}
\cline { 2 - 4 } & $\begin{array}{c}\text { Selected } \\
\text { Lagrange } \\
\text { multipliers } \lambda_{1}\end{array}$ & \multicolumn{2}{c}{$\begin{array}{c}\text { Associated } \\
\text { optimization } \\
\text { weight }\end{array}$} \\
\cline { 2 - 4 } & $C 1 \& C 2$ & $C 1$ & $C 2$ \\
\hline $\begin{array}{c}\text { Musculo-tendon } \\
\text { forces }\end{array}$ & $/$ & 1 & 1 \\
\hline & Hip & 0 & $1 \mathrm{e} 0$ \\
Joint contact & & & \\
forces & Medial & 0 & $2 \mathrm{e} 0$ \\
& tibiofemoral & & \\
& Lateral & 0 & $4 \mathrm{e} 0$ \\
& tibiofemoral & 0 & $1 \mathrm{e}-6$ \\
& Patellofemoral & 0 & $1 \mathrm{e} 0$ \\
\hline Ankle & 0 & 0 & $1 \mathrm{e}-6$ \\
& $\mathrm{ACL}$ & 0 & $1 \mathrm{e}-6$ \\
& $\mathrm{PCL}$ & 0 & $1 \mathrm{e}-6$ \\
Bigament forces & $\mathrm{PT}$ & 0 & $1 \mathrm{e}-6$ \\
& TiCaL & 0 & $1 \mathrm{e}-6$ \\
\hline \multirow{2}{*}{ CaFiL } & Femur & 0 & $1 \mathrm{e}-6$ \\
& Tibia & 0 & $1 \mathrm{e}-6$ \\
\hline
\end{tabular}


Table 2:

\begin{tabular}{|c|c|c|c|c|c|c|c|c|c|c|}
\hline & & & \multicolumn{2}{|c|}{ Subject 1} & \multicolumn{2}{|c|}{ Subject 2} & \multicolumn{2}{|c|}{ Subject 3} & \multicolumn{2}{|c|}{ Subject 4} \\
\hline & & & $C 1$ & $C 2$ & C1 & $C 2$ & C1 & $C 2$ & $C 1$ & $C 2$ \\
\hline \multirow{2}{*}{\multicolumn{3}{|c|}{ 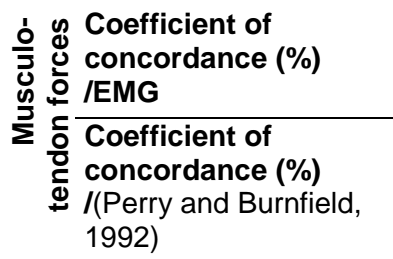 }} & 65.10 & 62.45 & 66.73 & 63.27 & 66.73 & 60.61 & 64.90 & 55.51 \\
\hline & & & 60.61 & 62.45 & 60.20 & 65.31 & 58.98 & 58.57 & 63.67 & 60.00 \\
\hline \multirow{8}{*}{ 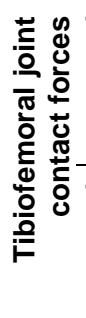 } & TBmed & Peak1 (BW) & 0.2195 & 0.0652 & 1.0232 & 0.4561 & -0.0162 & -0.1478 & 0.2211 & -0.0207 \\
\hline & & Peak2 (BW) & 2.4563 & 0.4861 & 2.1910 & 0.3451 & 3.6722 & 1.1144 & 3.5812 & 0.9833 \\
\hline & & RMSE (BW) & 0.9113 & 0.3120 & 0.9436 & 0.3409 & 1.3931 & 0.4981 & 1.3085 & 0.4186 \\
\hline & & $R^{2}$ & 0.7447 & 0.8896 & 0.9040 & 0.8769 & 0.7579 & 0.7915 & 0.6588 & 0.7777 \\
\hline & TBlat & Peak1 (BW) & 0.6108 & 0.3046 & -0.1997 & -0.5014 & 0.0077 & -0.0708 & 0.1265 & -0.0868 \\
\hline & & Peak2 (BW) & 2.0102 & 0.3947 & 1.1052 & -0.4678 & 1.6642 & 0.2049 & 2.4509 & 0.0775 \\
\hline & & RMSE (BW) & 0.7313 & 0.2187 & 0.4356 & 0.4317 & 0.6378 & 0.2412 & 0.8066 & 0.2450 \\
\hline & & $R^{2}$ & 0.7714 & 0.7669 & 0.7412 & 0.6599 & 0.7842 & 0.7725 & 0.8064 & 0.7280 \\
\hline
\end{tabular}


Figure 1:
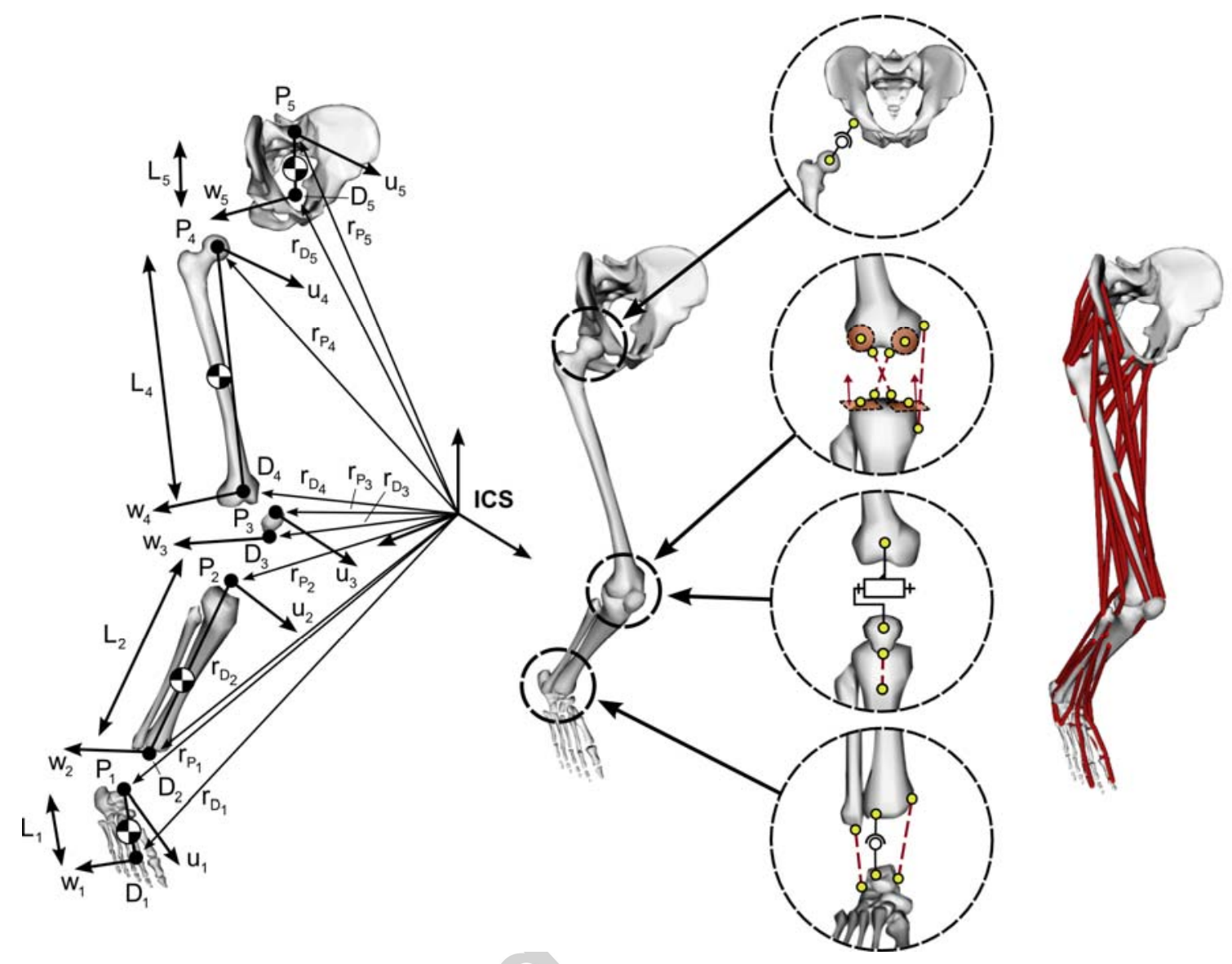
Figure 2:

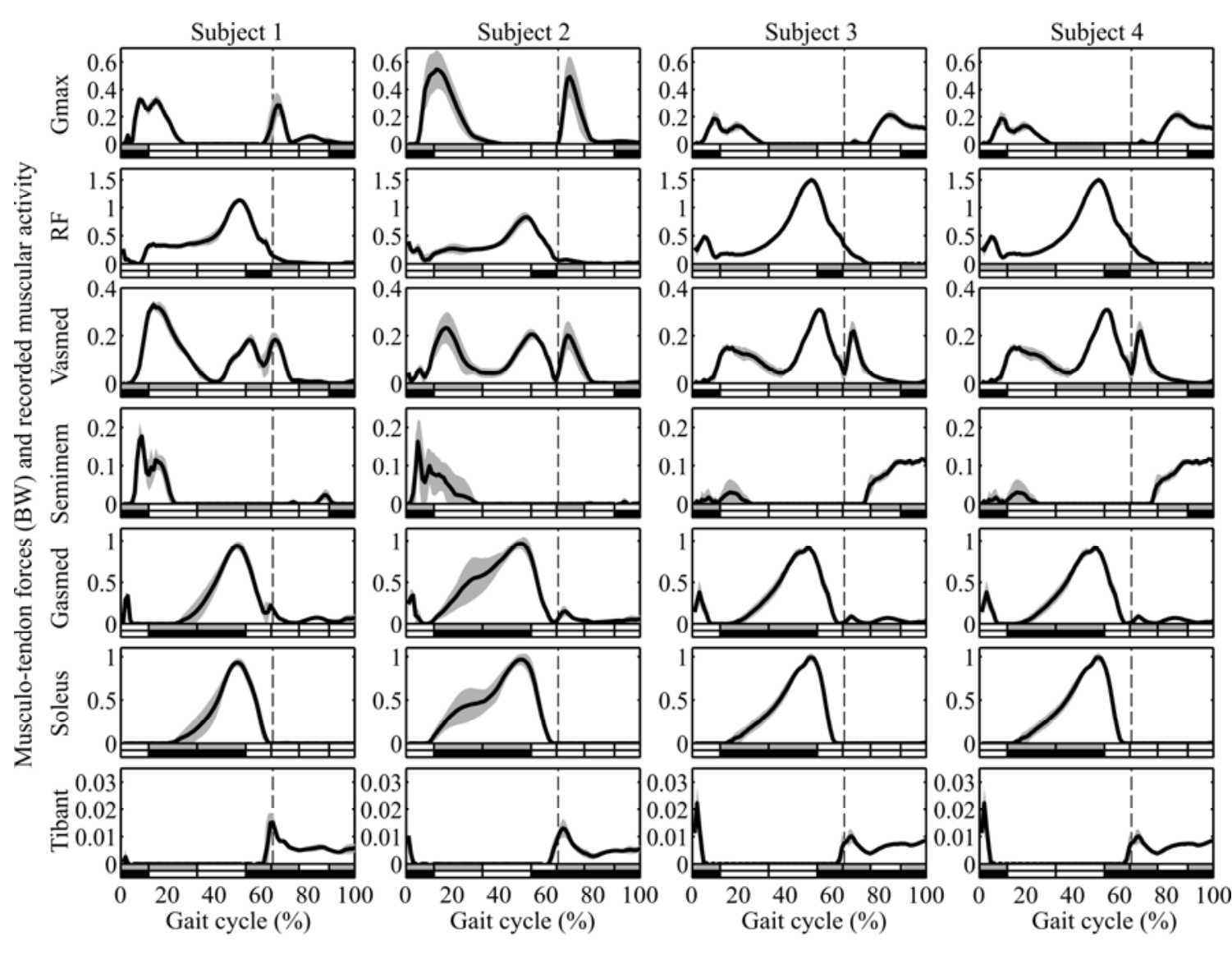


Figure 3:
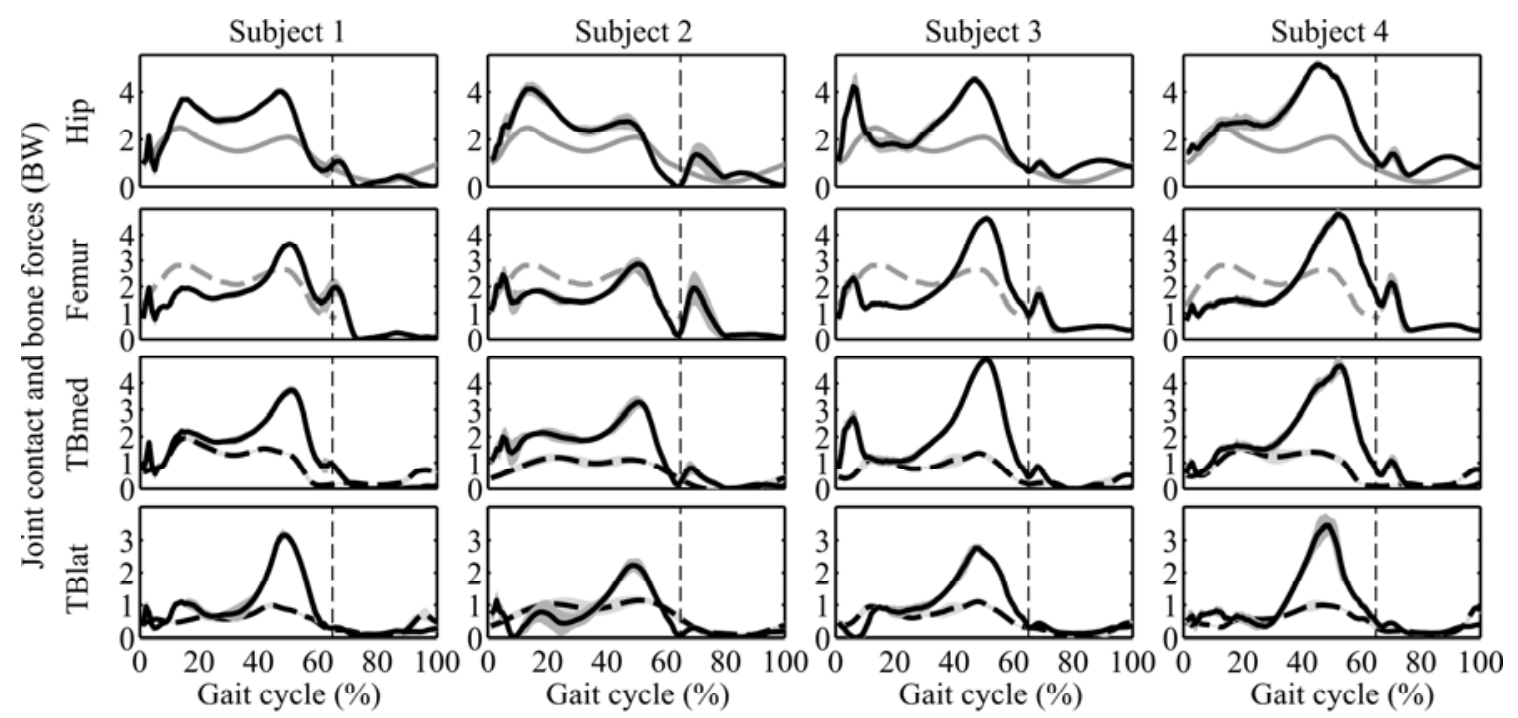

- Estimation - mean

-- Measurement - mean

- Stansfield et al., 2003 - mean

Estimation - std

Measurement - std

-- Lu et al., 1998 - mean 
Figure 4:
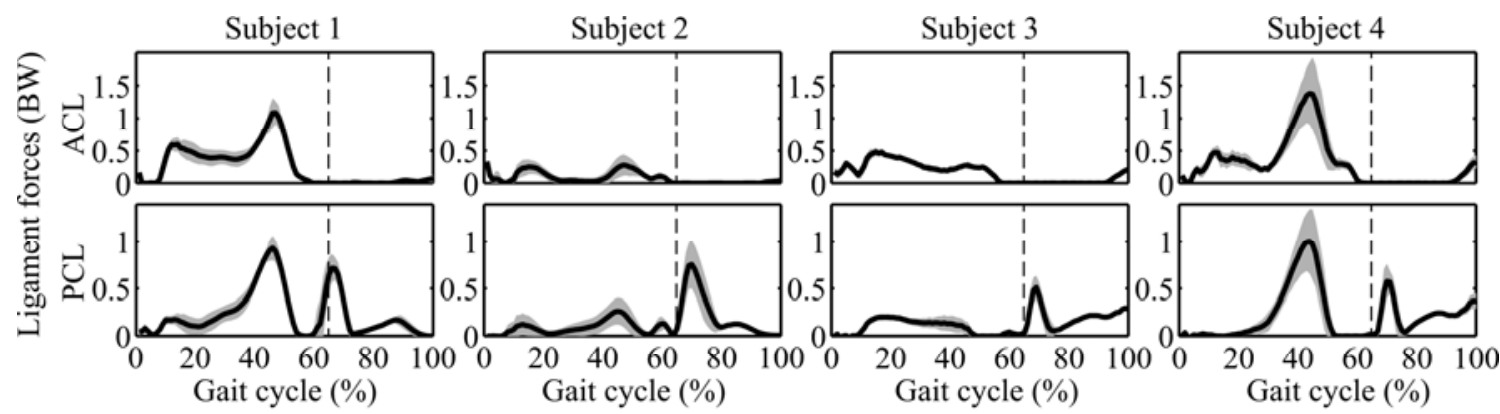

— Estimation - mean

Estimation - std 
Figure 5:

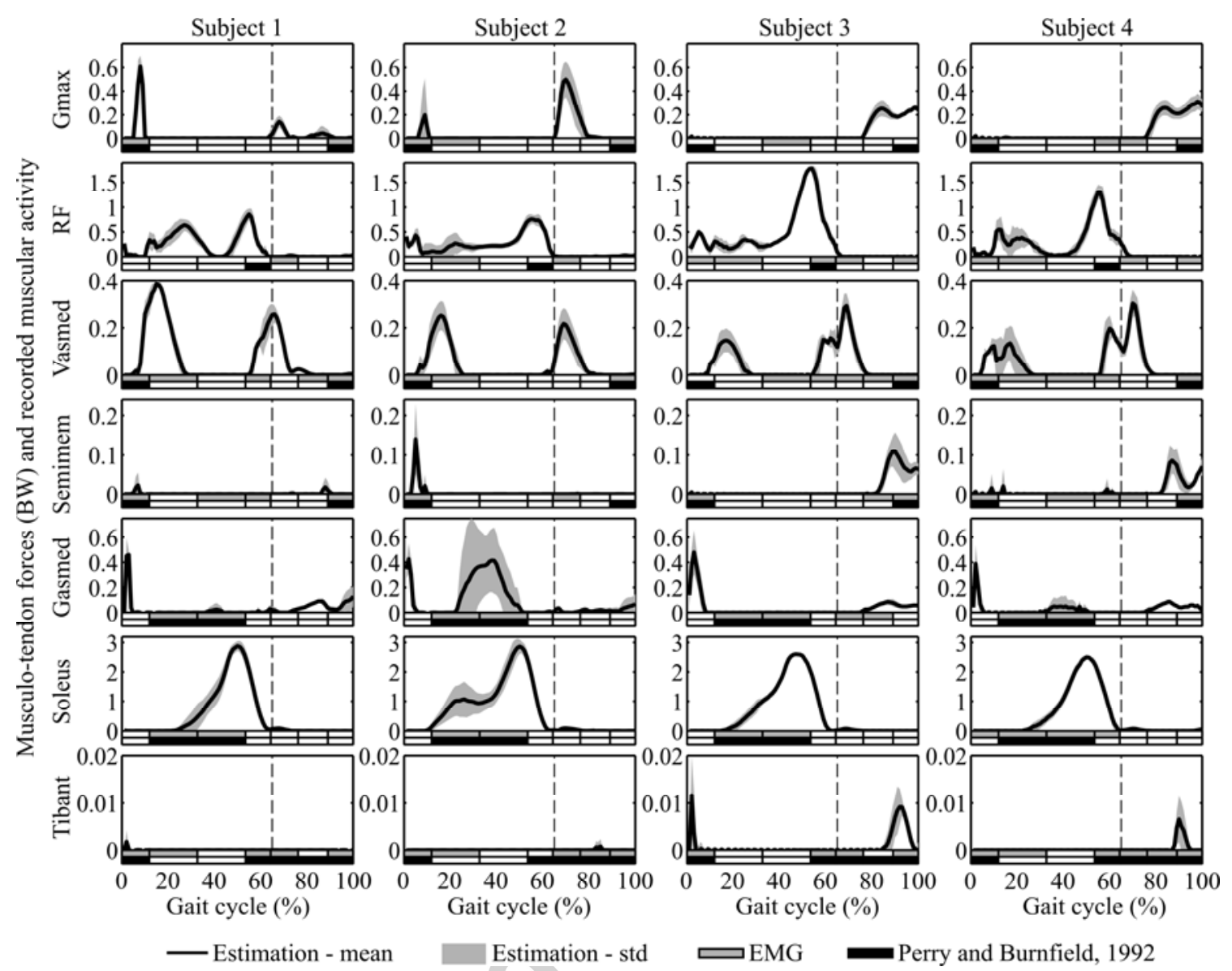


Figure 6:

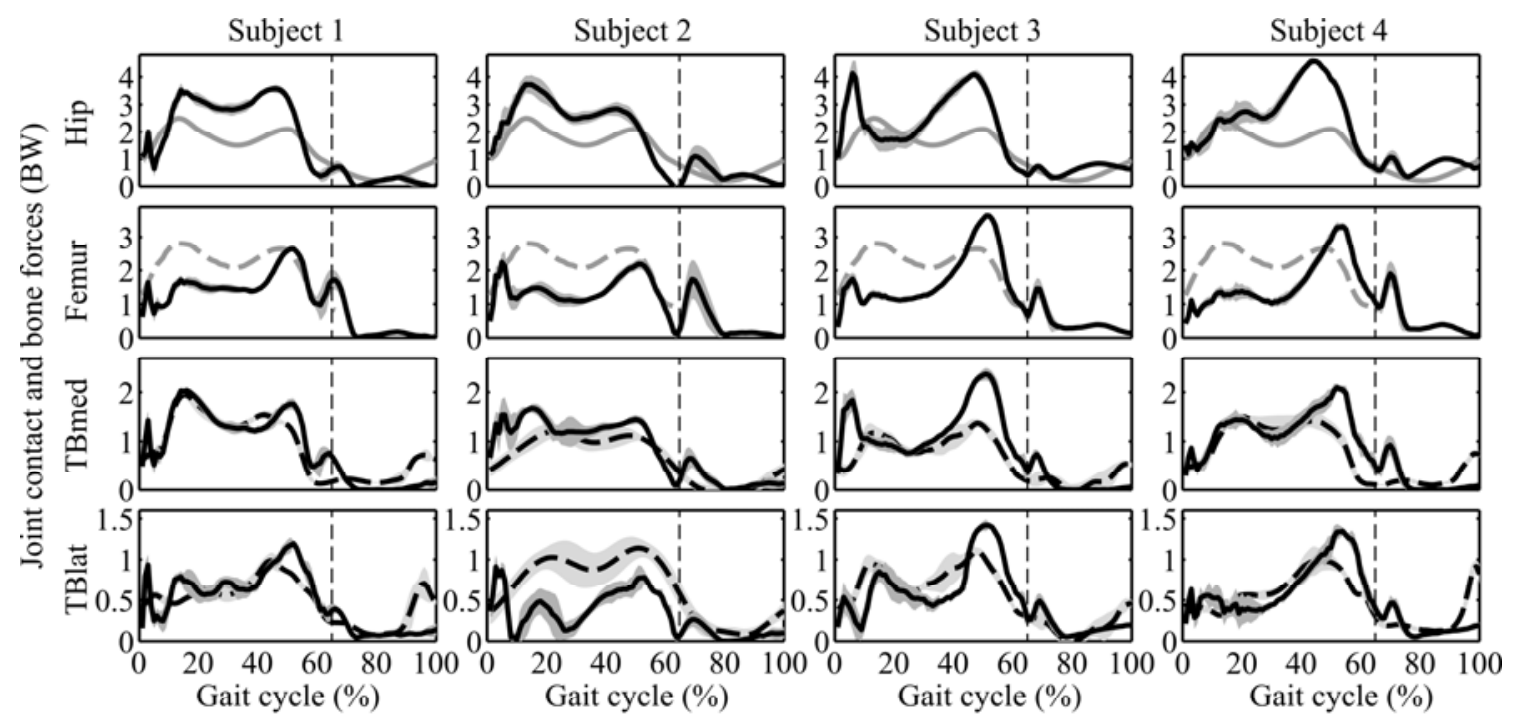

- Estimation - mean - - Measurement - mean - Stansfield et al., 2003 - mean

Estimation - std Measurement - std - Lu et al., 1998 - mean

Figure 7:

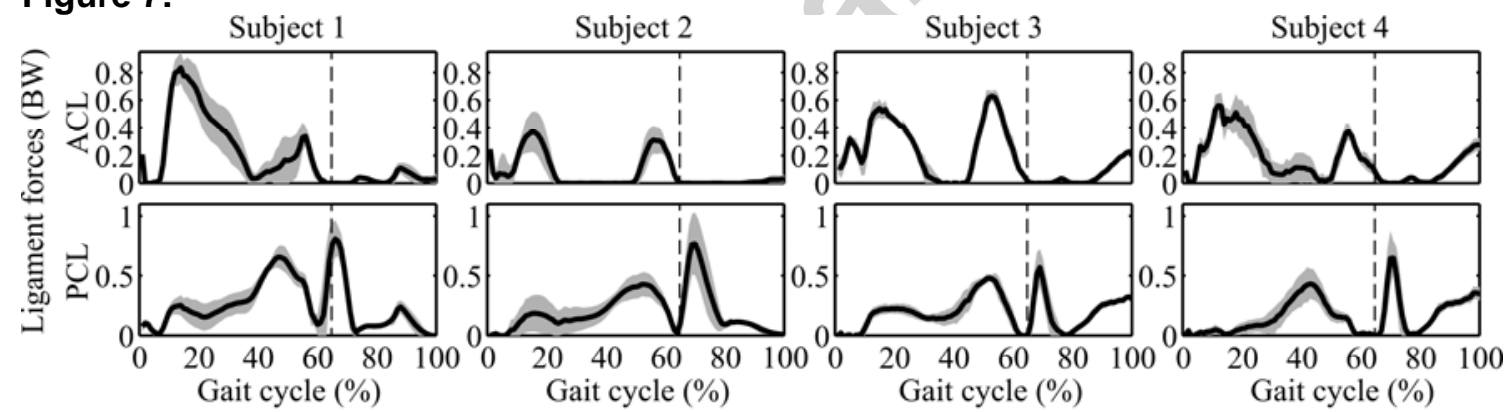

— Estimation - mean Estimation - std 